\title{
A View on the Comprehensive Care with Diabetes: What Do You Want to be When You Grow up?
}

\author{
Thalita Lacerda Nobre ${ }^{1, *}$, Sueli A. I. Fukushima ${ }^{2}$, Marcelo Masteguin ${ }^{3}$, Ana Cristina M. De Carvalho ${ }^{4}$, Flavia \\ Fuzzi $^{5}$, Carla Vieira ${ }^{6}$ \\ ${ }^{1} \mathrm{PhD}$, Psychology dept, Catholic University of Santos, Santos city, São Paulo State, postal code, Brazil \\ ${ }^{2}$ Occupational therapist. Specialist in public health. Member of attention to children with diabetes program in Guarujá, Guarujá city, \\ São Paulo State, postal code, Brazil \\ ${ }^{3}$ Endocrinologist doctor. Coordinator of attention to children with diabetes program in Guarujá, Guarujá city, São Paulo State, postal \\ code, Brazil \\ ${ }^{4}$ Pediatrician doctor. Expert in maternal and child nutrition and homeopathy. Member of attention to children with diabetes program in \\ Guarujá, Guarujá city, São Paulo State, postal code, Brazil \\ ${ }^{5}$ Nutritionist. Member of attention to children with diabetes program in Guarujá, Guarujá city, São Paulo State, postal code, Brazil \\ ${ }^{6}$ Nurse. Specialist in Occupational Health Nursing. Member of attention to children with diabetes program in Guarujá, Guarujá city, \\ São Paulo State, postal code, Brazil \\ *Corresponding author: thalita_l@yahoo.com.br
}

Received July 26, 2013; Revised February 09, 2014; Accepted February 11, 2014

\begin{abstract}
This research aims to relate the knowledge about Psychosomatic that understands diabetes is rooted in genetic and cultural practice with the Program Monitoring of Patients with Diabetes Mellitus 1 in the Guaruja city called "Sweeties of Guarujá", on the coast of São Paulo. From this conception, has established itself as a research problem that essential relationship can exist between investment in professional training activities and their influence in diabetes care.
\end{abstract}

\section{Keywords: Diabetes Mellitus Type 1, psychosomatic, self-care}

Cite This Article: Thalita Lacerda Nobre, Sueli A. I. Fukushima, Marcelo Masteguin, Ana Cristina M. De Carvalho, Flavia Fuzzi, and Carla Vieira, "A View on the Comprehensive Care with Diabetes: What Do You Want to be When You Grow up?.” American Journal of Medical Sciences and Medicine, vol. 2, no. 1 (2014): 1620. doi: 10.12691/ajmsm-2-1-4.

\section{Introduction}

The present study searched to analyze some characteristics in respect to investment in vocational training and its relationship with taking care of diabetes in population assisted by Programme for monitoring bearers of Diabetes Mellitus the type 1 (titled:"Sweeties of Guarujá"), situated I n Guarujá City, São Paulo coast. The structure and search results present in this Article were presented in 2011, in 16. Congress Multidisciplinar de Diabetes, organized annually by Association Assisting National the Diabetic (ANAD, Brazil).

This Programme for monitoring bearers of Diabetes Mellitus the type 1 began in 2004, from a Adjustment Term of Conduct issued by the Prosecutor's Office for Children and Youth of the District of Guarujá, when the mayor has committed to provide medical kit and supplies to all children and adolescents (up to 21 years old) suffering from Diabetes Mellitus who lived there.

In its first year, the program provided care to 18 patients, with the aim of providing full attention with interdisciplinary care and supply needed inputs to their treatment.
Since its inception until nowadays, users are referred from various health services in the county and receive specialized care-offered by the staff-on a fixed day of the week.

Currently, the program is targeted to 76 patients, with a team composed by: Endocrinologists, Pediatrician, Nutritionist, Nurse, Nursing Assistant, Psychologist and Occupational Therapist.

This professional team offers two types of calls:

- Individuals: to specific professionals, who analyze each case the course of the patient with the disease, as well as possible strategies to face this;

- Appointments group: With the aim of providing health education, solving doubts and promoting interaction among patients.

During the consultations with young patients, the interdisciplinary team realized it could be a connection between self care that patients have with their health and investment in their future.

This hypothesis came up because the team realized that youth service users population is in a phase of definitions regarding his future career, suffering with the parental demands, family and Brazilian society, which values strongly the professional career. According Levisky (apud Bock) [1], adolescence is characterized as a "stage of 
evolutionary development, when the child gradually passes into adulthood in accordance with environmental conditions and personal history." This means that, according to this author, adolescence is psychosocial, but it also cognitive.

Levisky (apud Bock) [1] adds further that adolescence is represented in accordance with the society and its historical moment, for him, currently, it has been treated in Western societies, as slow and painful, whereas, in the most primitive societies we can see passage rites that speed up and lessen the suffering moving to the adult world. Societies and cultures can increase adolescent crisis with their confusion, projecting their faults on them, causing them to receive and assimilate.

Based on these initial ideas, this research was designed with the following objectives: To demonstrate that the level of education influences the care of diabetes; Discuss regarding the importance of comprehensive care (beyond the disease) and its influence on care for the diabetes; Raise ideas about the degree of influence that a program of full attention encourages the development of diabetic adolescent self-investment.

The hypothesis designed by the team of professionals and also researchers was that teens who can create ambitious plans for the future have better adherence to diabetes treatment.

\section{Materials and Methods}

The data survey conducted during the months of March and April 2011, showed that the service was offered to 75 patients whose ages ranged between 0 and 23 years old. After 21 years old, the user is inserted into another monitoring program, however, there is a proposed extension of the "Sweeties of Guarujá" for the age group up to 25 years old.

For this reason, among the study subjects, we included also the population aged 22-25 years.

Users that compose the service are 52\% male and $48 \%$ female and age groups correspond to Figure 1 located in "results".

In addition, other data were collected, for example: "educational level", that can be observed "results" field.

The program includes assessment of the lower limbs sensitivity, performed by Semmes-Weinstein periodically. During the period data collection were evaluated $82.66 \%$ and $17.33 \%$ of users did not participate by the sensory evaluation.

Assessed subjects, 98.4\% had a sensitivity considered normal and only 1 user, the equivalent of $1.6 \%$ showed altered sensitivity (neuritis).

Face of this population, the multidisciplinary team of the "Sweeties of Guarujá" hypothesized that users who can construct an expectation on their future (professional, especially) tend to adhere to the treatment and to invest in self-care, especially related to diabetes care.

Therefore, the essential question which funded the research is how these adolescents can invest in their future and care of diabetes?

To start answering this question, the research was based on psychosomatic theories, especially psychoanalysis whose base is situated on the understanding that mental processes strongly influence the physiological processes of the body. In other words, the psychic character, even as Freud posited, is always associated with somatic character.

To answer this question, this research was based on psychosomatic theories, especially psychoanalysis whose base is situated on the understanding that mental processes strongly influence the physiological processes of the body. In other words, the psychic character, even as Freud posited, is always associated with somatic character.

Freudian psychoanalytic theory believes that the mental development of the subject is given by phases or stages that comprise the constitutional psychic structure later assumed by him. In accordance with was lived, in the end of childhood, the psyche of the subject may have different characteristics to mental functioning neurotic, psychotic, or be in pervesions field.

From the psychosomatic viewpoint, Debray [2] aware that there is a common psychological profile to insulindependent, however, "... the burden of diabetic disease is supported differently in accordance with the place for it occupied in the general economy of the person".

Thus, it is not possible to correlate the type 1 diabetes with a specific type of mental functioning, but the course the disease will take, may depend on the meaning that it acquires in the psyche of the diabetic person.

Debray [2] complements, in this sense, that the patient:

- The better your mental functioning (...) more the disease will show itself circumscribed assumed and conversely, if the mental functioning is changed (...), less the disease can be treated, it will become more invasive and impossible to be assumed, causing imbalance and early complications in diabetes for example.

Therefore, how much more preserved the person mental functioning is, much larger can be the chances that he can invest in itself care.

Thus, we can understand that there is a strong relationship between the place taken by the disease inside the diabetic subject psyche and his psychic functioning mode. Moreover, it is possible to consider the large correlation among disease, how the person feels his existence in the present moment and ideals for himself life construction.

In order to amplify these questions, it is interesting to turn to Pierre Marty (1980), who in his studies of psychosomatic understands that the outbreak of a disease is related to two key factors: environmental factors and life history of the subject.

So, put another way, we can comprehend that in diabetes genesis there is an occurrence of genetic factors (relating to family heirlooms) associated with factors related to the life history of this person.

Thus, there is no way to predict the onset of disease type 1 and no way to understand the factors that influence the course and treatment of it.

For Mello Filho (apud Burd) [3], "diabetes tends to cause in patients: insecurity and loss of self-esteem, passivity and dependence, sexual maladjustment, masochism and self-aggression, defiance, anxiety and depression."

However, as stated earlier, the onset of mental disorders arising from the existence of the disease will depend on the psychic economy of the subject and the environment in which he lies. 
Concerning to the environment, may be mentioned essential importance and relevance of the family that will provide treatment to the patient. In Burd's [3] words:

- The treatment requires control, and it will depend critically on how carriers deal with their patients conditions, depending on their prior learning and experiences within the culture to which they belong. In this sense, the individual experience of illness not only results in the biological expression, as well as the subjective perception and cultural influences involved in the disease process.

And these cultural influences mentioned by the author, are related to family (especially the essential figures of father and mother) and the way in which the subject is inserted.

For Freud [4], at the end of childhood, are constituted two essential psychic instances that result from identification with their parental figures: they are named superego and ego ideal. In his words: "... the ego ideal is the precipitate of parents's old image, the expression of admiration for the perfection that the child until then had attributed to them."

According to Freud, even that sometimes both of the concepts are treated like equal, the superego corresponds to obedience to the laws formed in which culture and the ego ideal is responsible for the ideals creation, it means, by the investment that the person will do to become someone he considers best in the future, starting from which he received from his parents.

From psychosomatic point of view, Debray [2] synthesizes: "there seems no doubt that there is indeed a link between mental organization of a person and his way of dealing-or not dealing-a severe and irreversible, such as diabetes, but the role and the weight assigned to that relationship lends itself to numerous discussions".

Thus, linking the Freudian postulates that considers the ego ideal as psychical agency responsible for the investment of the individual on his future with psychosomatic conceptions, it was possible to establish a criterion for research: which expectations have the "Sweeties of Guaruja" in relation to their own professional formation.

The research was conducted by interviews and questionnaires with users of the "Sweeties of Guaruja," where it was possible to construct figure with the results.

\section{Results}

About the program users, researchers extracted the information about the age, which is composed as shown in the following figure:

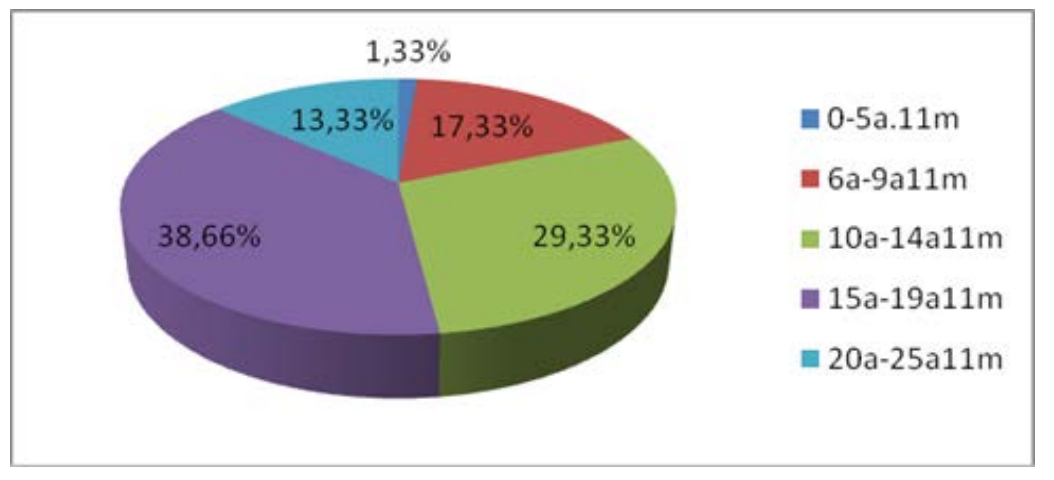

Figure 1. Age group total population

So, as we can see, the vast majority of respondents were located in the corresponding period of the early productive life, the period in which the young begin to define their professional activities (38,66\% were between 15 and 19 years and 13,33\% were between 20 and 25 years old). It is also possible to consider that a significant portion is at the beginning or already living the period of puberty (which 29.33\% was between 10 and 14 years), a period in which, commonly, they start to define their future interests.

With all subjects studied, researchers wondered what time each lived with diabetes diagnosis and the following data were obtained:

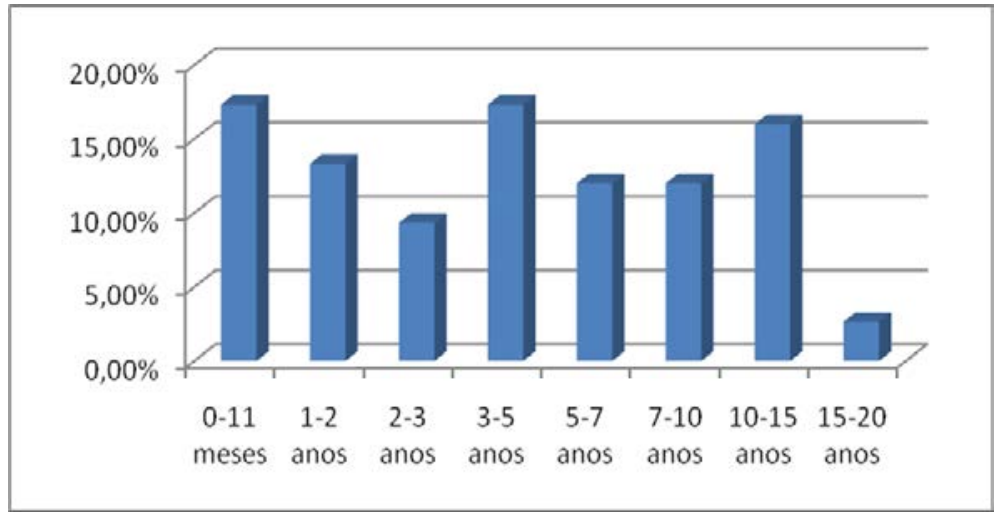

Figure 2. Time living with diabetes tipe 1 diagnosis

In this sense, it can be observed that there are considerable differences, placing the population especially among those who live with the disease for more than three years, or less than one year. These data can be correlated 
with the previous figure, where most of the studied population lies in the age group between 10 and 19 years (67.99\%).

To obtain other relevant data from the studied total population, the researchers extracted only those subjects who were nearest to put into practice their personal desires.
Therefore, the population of subjects studied was between 15 and 23 years (during the months of March and April 2011), a total of 28 respondents.

Within this population was initially studied the level of education they were in, as shown in the following figure:

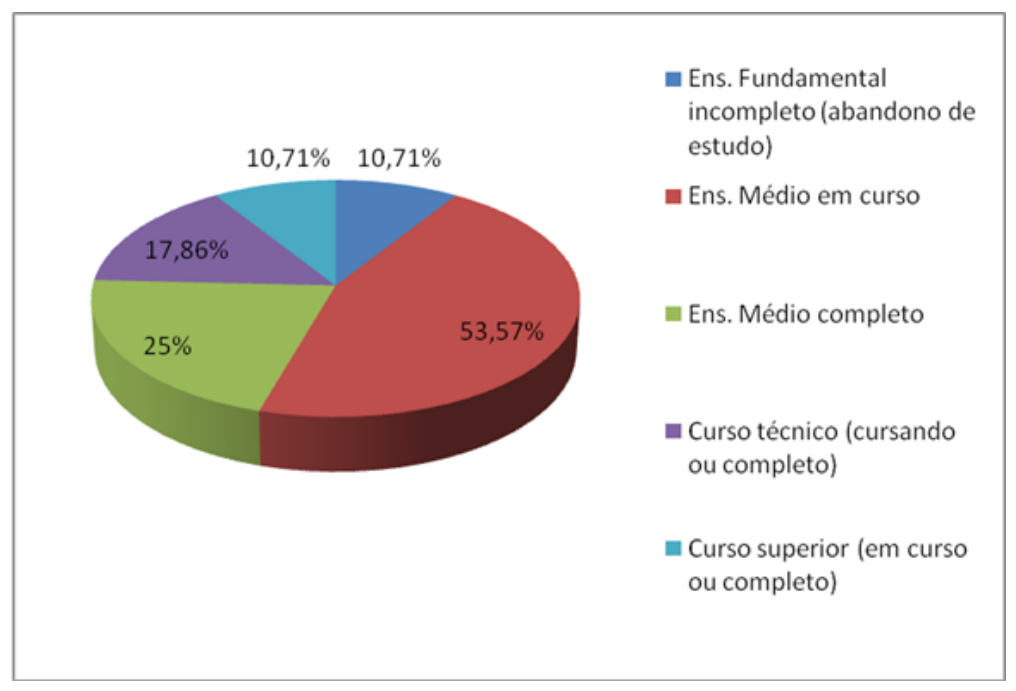

Figure 3. Educational level of the population between 15 and 25 years

This figure cited above, shows that the two most significant slices population (53.57\% and 25\%) attended or are attending high school education. In this regard, it was possible to consider that the population of users that make up the program "Sweeties of Guaruja" presents a characteristic heterogeneous with respect to socio cultural and economic family level.

As this is a service practiced in a municipal public institution, the researchers' hypothesis about the data in Figure 4 is that the subjects that comprise the percentage of college or technical family has better financial conditions than the population remaining.
These hypotheses will be tested in subsequent work by the researchers. However, considering that currently have government incentives for entering the population in technical training courses and universities, the conclusion of the researchers is that there might be some personal characteristics in terms of self-esteem and self-investment that may interfere with admission in these courses beyond the school.

Another important finding in this study was obtained on the expectation of the subjects facing their professional future in the short and medium term, as can be seen in the following figure:

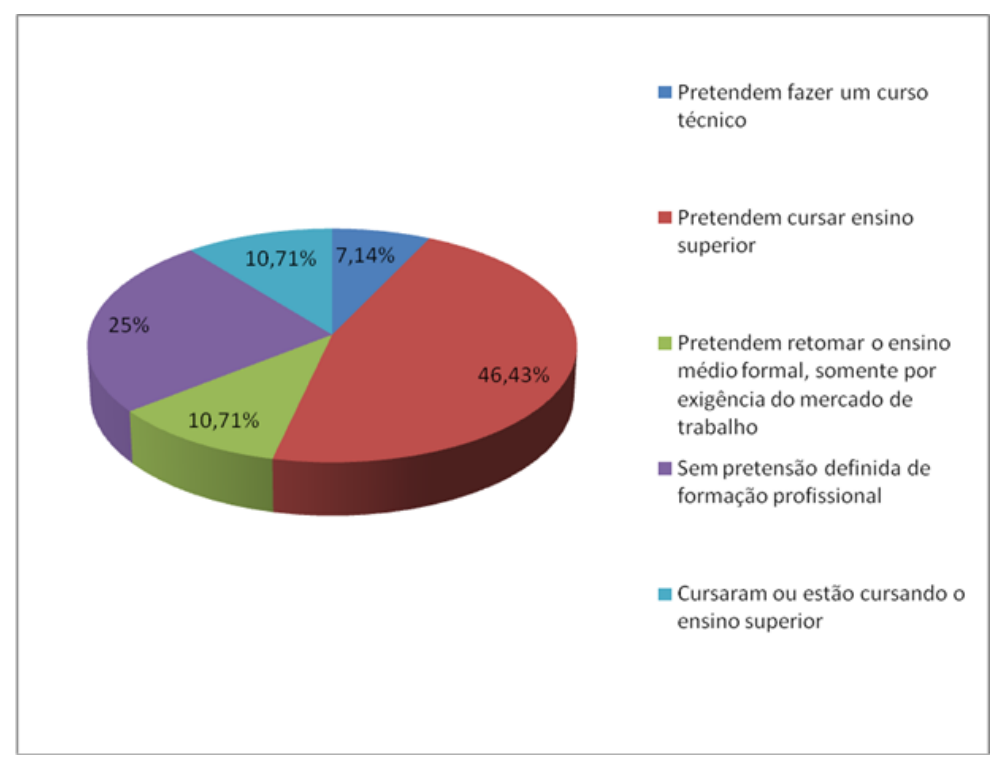

Figure 4. Pretension for the future Professional in the researched population

The figure above seem to support the initial hypotheses raised by previous data, since much of the population of young people studied (46.43\%) reported an interest in continuing the formal higher education.

Although these subjects represent a sizeable share of research, represents less than half of the population.
This data can be worrisome with respect to young investment in yourself and in your future, if other data are considered significant as the $25 \%$ of the population that has no pretension defined by professional formation or $10.71 \%$ who are not currently studying and want to return to high school only by requirement for the job market. 
These data allow researchers to conjecture that it is difficult to invest in the future ideals of this share of young population users program researched.
These hypotheses formulated by the researchers, are more significant if we consider the following data below regarding the inclusion of these subjects in the current labor market, as shown by the following figure:

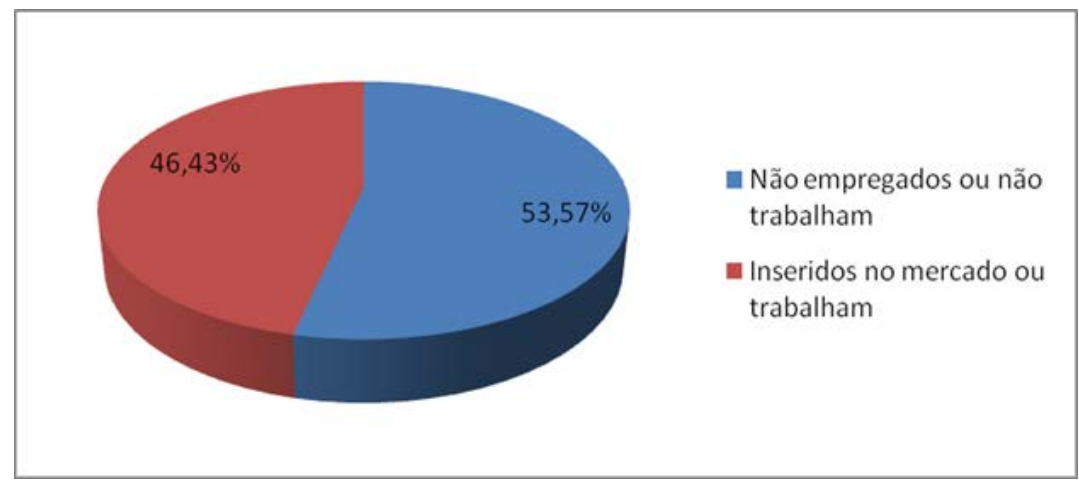

Figure 5. Insertion into labor market

From the interpretation of previous data obtained, it is possible to consider that may have deficiencies regarding the adequacy of youth into labor market.

\section{Conclusion}

Were found deficient expectations with respect to professional investment in a significant share of the population studied (35.71\%). Thus, in correlation to the studies psychoanalytic and psychosomatic who understand the psyche more preserved also preserves the ability to invest in yourself and the ideals established, it can be concluded that the population of young subjects in this study presents some difficulty in this requirement.

Nevertheless, much of the population has good diabetes care, as showed in the result of lower limbs sensitivity examination.

These considerations allow researchers concluded from the results that, although the difficulty in creating strategies that address the self-care, from the care of diabetes to the planning of future professionals, the population is not at extremely worrying levels, which enables interdisciplinary team of researchers involved in the care of these patients seek external incentive strategies.

One of these strategies could be established from this study was the possible incentive of youth studies, leading to therapeutic groups and educational information regarding the professional market and assisting in the improvement of self-esteem.

In addition, we intend to follow up during the next few months, taking into account the results of tests - dextro glycated hemoglobin of patients analyzed in order to ascertain whether there was a change in these rates and what they may mean in terms of changes in habits with care geared themselves.

Data concerning these strategies will be compiled and form strategic studies later.

\section{References}

[1] Bock, A.M.B. “Adolescence as a Social Construction-a Research on the Concept On Books Applied to Parents and Educators”. Revista Semestral da Associação Brasileira de Psicologia Escolar e Educacional (ABRAPEE) • Volume 11 Número 1 Janeiro/Junho $2007 \cdot 63-76$

[2] DEBRAY, Rosine. O equilíbrio psicossomático: e um estudo sobre diabéticos. São Paulo: Casa do Psicólogo, 1995 (1st edition), pp. 264.

[3] MELLO FILHO, Julio de e BURD, Miriam (org.). Doença e família. São Paulo: Casa do Psicólogo, 2004, pp. 412.

[4] FREUD, Sigmund (1933 [1932]). A dissecção da personalidade psíquica. ESB, vol. XXII, 1996, pp. 283. 